This suggests other factors must be important in predicting COPD readmissions.

\section{P157 CANCER PATIENTS WITH SEVERE COMMUNITY ACQUIRED PNEUMONIA HAVE POORER OUTCOMES DUE TO INCREASED ILLNESS SEVERITY AND SEPTIC SHOCK AT ADMISSION TO INTENSIVE CARE}

${ }^{1} \mathrm{RJ}$ José, ${ }^{2} \mathrm{AO}$ Mohammad, ${ }^{3} \mathrm{JP}$ Goldring, ${ }^{1} \mathrm{RC}$ Chambers, ${ }^{1} \mathrm{JS}$ Brown, ${ }^{4} \mathrm{~B}$ Agarwal. ${ }^{1}$ Centre for Inflammation and Tissue Repair, Division of Medicine, University College London, London, UK; ${ }^{2}$ Department of Thoracic Medicine, Minia University, Elminia, Egypt; ${ }^{3}$ Department of Thoracic Medicine, Royal Free Hospital, London, UK; ${ }^{4}$ Department of Intensive Care Medicine, Royal Free Hospital, London, UK

\subsection{6/thoraxjnl-2014-206260.286}

Introduction Patients with community acquired pneumonia (CAP) and an underlying diagnosis of cancer have worse outcomes. However, the characteristics of cancer patients with severe CAP admitted to intensive care units are not well defined. Methods An observational study of patients admitted to a University hospital ICU with a primary diagnosis of CAP between January 2006 and October 2011.

Results 96 patients met our inclusion criteria for a diagnosis of severe CAP. 19 (19.8\%) had cancer at the time of admission to ICU (57.9\% with haematological malignancy and $42.1 \%$ with solid organ cancer). There were no statistically significant differences in age, gender or co-morbidities between those with and those without cancer. Patients with cancer had significantly higher median [IQR] APACHE II (25 [20-19] vs 20 [16-24]; p = 0.009), SAPS (51 [42-62] vs 42 [34-53]; $\mathrm{p}=0.039)$ and SOFA (12 [1013] vs 9 [4-12]; $\mathrm{p}=0.018$ ) scores and a longer median [IQR] time interval between hospital and ICU admission (2 [1-5] vs 1 $[0-3]$ days; $p=0.049)$. There were no statistically significant differences in the proportion of patients receiving mechanical ventilation or renal support and no differences in the duration of mechanical ventilation or duration of ICU or hospital stay. Patients with cancer included a significantly greater proportion of patients receiving vasopressors $(89.5 \%$ vs $63.6 \%, \mathrm{p}=0.030)$ and a markedly increased ICU $(68.4 \%$ vs $31.2 \%, \mathrm{p}=0.004)$ and hospital mortality $(78.9 \%$ vs $33.8 \%, p=0.001)$. There were no significant differences in leukocyte counts, CRP, clotting (PT, APTT and INR), renal function (urea and creatinine) or liver function (AST and ALT). There were no significant differences in heart rate, temperature, systolic blood pressure or oxygenation index. However, patients with cancer had significantly lower median diastolic blood pressure $(40 \mathrm{mmHg}$ vs $50 \mathrm{mmHg}, \mathrm{p}=0.026)$.

Conclusion Cancer patients with severe CAP continue to have an increased risk of death that appears to be related to increased illness severity at the time of ICU admission associated with septic shock. A delay in recognising the need for intensive care support in cancer patients with severe CAP may possibly explain the increased illness severity at the time of ICU admission.

\section{P158 EVALUATION OF VITAL CAPACITY CHANGES IN SPINAL INJURED PATIENTS DURING EPISODE OF SEPSIS}

M Nasher, AC Pocock, T Ward, T Bongers. Southport and Ormskirk Hospital NHS Trust, Southport, UK

10.1136/thoraxjn-2014-206260.287

Introduction Respiratory complications have been suggested as cause of death in approximately $60 \%$ of spinal cord injured patients requiring ventilation after spinal cord injury. ${ }^{1}$ The vast

\begin{tabular}{|c|c|c|c|c|}
\hline Level & ASIA & Baseline VC & VC when unwell & Change in VC $(\%)$ \\
\hline C4 & A & 1200 & 600 & $600(50 \%)$ \\
\hline C4 & A & 2200 & 500 & $1700(77 \%)$ \\
\hline C4 & c & 2500 & 650 & $1850(74 \%)$ \\
\hline C4 & A & 2900 & 1500 & $1400(48 \%)$ \\
\hline C4 & c & 1630 & 980 & $650(40 \%)$ \\
\hline C4 & A & 3000 & 2930 & $70(2.3 \%)$ \\
\hline $\mathrm{C} 4$ & A & 1200 & 1000 & $200(16 \%)$ \\
\hline $\mathrm{C} 4$ & A & 3000 & 1590 & $1410(47 \%)$ \\
\hline $\mathrm{C} 4$ & A & 2550 & 1750 & $800(31 \%)$ \\
\hline C6 & B & 1800 & 650 & $1150(63 \%)$ \\
\hline $\mathrm{C} 6$ & B & 3400 & 800 & $2600(76 \%)$ \\
\hline C6 & B & 3570 & 2650 & $890(25 \%)$ \\
\hline T4 & A & 4000 & 3480 & $520(13 \%)$ \\
\hline T8 & A & 4000 & 1680 & $2320(58 \%)$ \\
\hline T8 & c & 3250 & 1920 & $1330(41 \%)$ \\
\hline T9 & D & 1400 & 800 & $600(43 \%)$ \\
\hline
\end{tabular}

majority of these respiratory complications are due to infections i.e. pneumonias. It has been postulated that infections trigger a general inflammatory response which directly affects respiratory muscle strength and worsens respiratory function, which can cause respiratory failure. ${ }^{2}$ All patients with a high spinal injury (> T1) or respiratory impairment have their vital capacity (VC) measured routinely at least once daily. We designed a project to assess if significant forced vital capacity (FVC) changes occur in spinal injury patients during an episode of sepsis.

Methods In this retrospective review we collected data from all our spinal injury patients with an episode of sepsis (pneumonia or urinary) between March 2010 and February 2013.

Results A total of 16 episodes were recorded in 14 patients (2 female, 12 male) with an average age of 61.8. Level of spinal cord injury varied from C4-T9 and the majority had ASIA (American Spinal Injury Association) grade A. Of all 16 episodes of sepsis, $6(37.5 \%)$ were diagnosed as pneumonia. $10(62.5 \%)$ were of urinary tract origin with positive urine culture. Blood cultures were positive in 4 cases, negative in 11 and not available in 1 . FVC ranged from $4000 \mathrm{ml}$ to $1200 \mathrm{ml}$. VC changes were more profound with respiratory infection as we observed an average FVC change of $1450 \mathrm{ml}(50-77 \%)$ for the diagnosis of pneumonia and $862 \mathrm{ml}(2.3-58 \%)$ for urinary tract infection Conclusions Systemic infection causes significant changes in vital capacity suggesting direct effect of the inflammatory process on diaphragmatic and respiratory muscle function. These VC changes are more profound with respiratory infection and in our study varied from 50\%-77\% reduction from the baseline. Reduction in $\mathrm{VC}$ is an important sign of clinical deterioration and should be routinely measured in any patient with spinal cord injury to prevent respiratory compromise and respiratory failure.

\section{REFERENCES}

1 Watt J et al. Spinal Cord.2011:49:404-10

2 Boczkowski J. Am J Respir Crit Care Med.2004;169:662-663

\section{P159 WEANING AND LONG TERM VENTILATION OUTCOMES IN SPINAL INJURY PATIENTS AFTER REFERRAL TO A REGIONAL SPINAL INJURY CENTRE}

AC Pocock, M Nasher, T Ward, T Bongers. Southport and Ormskirk Hospital NHS Trust, Southport, UK

10.1136/thoraxjnl-2014-206260.288 


\begin{tabular}{lll} 
Abstract P159 Table 1 & & \\
\hline Level of Injury & Number & $\%$ \\
\hline C1-3 & 10 & $23 \%$ \\
C4-5 & 23 & $54 \%$ \\
$>C 5$ & 10 & $23 \%$ \\
\hline
\end{tabular}

Introduction Difficult and slow weaning of ventilated patient will have been observed by staff in many critical care units ${ }^{1}$. A National Association for Medical Direction of Respiratory Care (NAMDRC) Consensus Conference suggested that 20\% of such patients had neurological disease ${ }^{2}$.

The incidence of respiratory failure following acute cervical spinal cord injury (ASCI) ranges between $22.6 \%$ and 57\% and the average time to wean from ventilator support was found to be 36 days. Weaning for such patients should therefore take place in an intermediate care facility and be slow paced ${ }^{2}$. Previous data from our unit did suggest a successful wean in about $70 \%$ of patients admitted to this regional spinal injury unit ${ }^{1}$. We therefore wanted to review our recent results (Nov 2009 - Nov 2012) with previous standards.

Methods We performed a retrospective review of all patients admitted from November 2009 to November 2012 for respiratory weans following spinal cord insult.

Results 43 patients ( 35 male and 8 female) were admitted to the spinal critical care unit for weaning (14.33 patients per year). Average age was 54.7 years for male and 55.4 years for females. The level of injury is illustrated in the table below:

Of the 43 patients, 35 were successfully weaned; the rest were either partially weaned or not weaned.

7 of the 10 Level C1-3 injury patients were not weaned or were only partially weaned. The remaining 3 patients of Level C1-3 injury (incomplete) were weaned. 1 patient with Level C6 injury was only partially weaned but was 77 years of age.

Conclusions Review of the period from 2009-2012 is very encouraging, suggesting weaning success in line with national and international centres. Further reviews will focus on duration of wean and the effect of co-morbidities and age on the weaning outcome. Further attention needs to focus on quality of life in the weaned and not weaned patient group.

\section{REFERENCES}

1 Watt I et al. Brit I Intensive Care AUTUMN/ 2008;95-102

2 Maclntyre NR et al. Chest 2005:128:3937-3954

increased pulmonary vascular resistance, right ventricular failure and death. Survival is strongly linked to functional class with patients persisting in WHO class IV surviving less than one year. Such patients commonly require repeated hospital admissions with intractable symptoms due to right heart failure. Although specialist palliative care involvement is recommended in current guidelines for the management of $\mathrm{PAH}$, no formal recommendations exist presently to guide clinicians on timing of referral.

The aim of this study was to outline current practice in this area and define the potential workload and role of specialist palliative care services.

Methods Data was collected retrospectively for all patients within our national PAH service who died over a one year period (June 2013-June 2014). We specifically looked at timing of referral and involvement of palliative care specialists, WHO functional class, clinical course prior to death and prognostic indicators of deterioration.

Suitable patients were identified from the PAH and palliative care databases. Patient notes were reviewed to identify WHO class, clinical course prior to death and documented evidence of specialist palliative care involvement.

Results

- 31 patients were identified; (14 male, 17 female; 19 (61\%) WHO IV, 9 (29\%) WHO III, 3 (10\%) WHO II).

- Only 11 (35\%) had documented evidence of specialist palliative care involvement.

- $7(22 \%)$ received input whilst in hospital, $4(13 \%)$ in the community.

Conclusions The majority of our patients did not receive specialist palliative care support during the final stages of their disease. Whilst the majority (61\%) of patients were functional class IV prior to death, 39\% were functional class II or III. Progressive deterioration and increased burden of symptoms over time preceding death were commonly noted. Whilst the specialist PAH nurses and clinicians offer palliative care and support, our data suggests that a review of the timing, organisation and documentation of referral to specialist palliative care services requires consideration.

\section{P161 ASSESSMENT OF AGE-ADJUSTED D-DIMER CUT-OFF VALUES IN INVESTIGATING VENOUS THROMBOEMBOLISM IN OLDER PATIENTS: A RETROSPECTIVE ANALYSIS}

SSM Lau, GEJ Murphy. Southern General Hospital, Glasgow, UK

10.1136/thoraxjnl-2014-206260.290

\section{Pulmonary arterial hypertension: diagnosis, management and outcomes}

\section{P160 THE ROLE OF SPECIALIST PALLIATIVE CARE SERVICES IN THE MANAGEMENT OF PATIENTS WITH PULMONARY ARTERIAL HYPERTENSION; A REVIEW OF CURRENT PRACTICE}

SC Woolcock, J De Soyza, R Crackett, M Day, AJ Fisher, J Lordan, G MacGowan, PA Corris. National Pulmonary Hypertension Service (Newcastle), Institute of Cellular Medicine, Newcastle University and the NUTH NHS Foundation Trust, Newcastle Upon Tyne, UK

10.1136/thoraxjnl-2014-206260.289

Introduction and objectives Pulmonary Arterial Hypertension $(\mathrm{PAH})$ is a severe, progressive condition characterised by
Introduction and objectives The specificity of D-dimer testing in detecting venous thromboembolism (VTE) appears to fall in older patients as D-dimer concentrations increase with age. There has been interest in the use of age-adjusted D-dimer cutoff values to increase the specificity in older patients. The objective of this study was to review the diagnostic accuracy of Ddimer testing in older patients with suspected VTE in our population, comparing conventional and age-adjusted D-dimer cut-off values.

Methods A retrospective study from a large teaching hospital in the UK was undertaken. 389 data episodes were compiled from suspected VTE presentations during two months in 2013. Patients were assessed using a combination of clinical probability scores and D-dimer measurement (D-dimer HS assay, Instrumentation Laboratories). Conventional $(230 \mathrm{ng} / \mathrm{ml})$ and age-adjusted 